\title{
A Mathematical Tightening of Instantaneous Indoor and Outdoor Dry-Bulb and Wet-Bulb Temperature Tolerances
}

\author{
Xinhao Hu ${ }^{1}$, Zhongbin Zhang ${ }^{1,2, *}$ and Dandan Cai ${ }^{1}$ \\ 1 Engineering Laboratory of Energy System Conversion and Emission Reduction of Jiangsu Province, School \\ of Energy and Mechanical Engineering, Nanjing Normal University, Nanjing 210042, Jiangsu, China; \\ 20130625@stu.njnu.edu.cn (X.H.); 1546897918@qq.com (D.C.) \\ 2 Zhenjiang Institute for Innovation and Development, Nanjing Normal University, \\ Nanjing 210042, Jiangsu, China \\ * Correspondence: zhangzhongbin@njnu.edu.cn; Tel.: +86-135-1511-2510
}

Received: 10 November 2019; Accepted: 16 March 2020; Published: 19 March 2020

check for updates

\begin{abstract}
To reduce the inaccuracy in energy efficiency evaluation, indoor and outdoor dry-bulb and wet-bulb temperature (D\&WBT) tolerances in the currently enacted Chinese room air conditioner (RAC) national standard were tightened into narrower intervals in this investigation. Characteristics of cooling capacity (CC) and energy efficiency ratio (EER) changing with D\&WBTs were analyzed based on performance tests. AICc (corrected Akaike Information Criterion) was applied to determine the best fitted 3D curve equations of CC and EER to find the intervals of gradient extrema of CC and EER. The corresponding intervals of indoor and outdoor D\&WBTs were concluded as the tightened D\&WBT tolerances. For illustration, based on the performance tests of 154 working conditions, the instantaneous indoor and outdoor D\&WBT tolerances in nominal refrigerating working conditions were respectively tightened from the original $\pm 0.5 / \pm 0.3^{\circ} \mathrm{C}$ into $\pm 0.3 / \pm 0.2{ }^{\circ} \mathrm{C}$ (indoor tolerances) and $\pm 0.4 / \pm 0.3{ }^{\circ} \mathrm{C}$ (outdoor tolerances). EER variation rate thus decreased from $2.11 \%$ to $1.03 \%$ (indoor) and $2.11 \%$ to $1.25 \%$ (outdoor).
\end{abstract}

Keywords: dry-bulb and wet-bulb temperatures; tolerances; Chinese national standard; room air conditioner; performance experiment

\section{Introduction}

In light of the climate objective in the Paris Agreement of limiting global mean temperature increase to well below $2{ }^{\circ} \mathrm{C}$ and pursuing efforts to limit it further to $1.5^{\circ} \mathrm{C}$ [1], governments worldwide have spared no effort in reducing carbon emissions. Over the past years, electricity consumption across Europe has increased significantly and accounts for around $21 \%$ of final energy demand, and the domestic sector alone accounts for almost $25 \%$ of final energy consumption and almost $30 \%$ of electrical energy demand. One key drive for increasing electrical demand in Europe is the rapid increasing number of household appliances with RAC (room air conditioner) as a major component [2]. In Japan, from 1990 to 2005, the total emissions of $\mathrm{CO}_{2}$ derived from RAC increased by $1.47 \mathrm{Mt}-\mathrm{CO}_{2}$, which corresponds to an increase of $16.5 \%$ relative to the 1990 level of emissions [3]. As the third largest market of RAC in the world, the demand in Japan reached 8.35 million units with a 3.1\% increase [4], and its residential electricity consumption in 2014 was up to 986 PJ [5]. In the U.S., 1410 billion $\mathrm{kW} / \mathrm{h}$ of electricity was used by the residential sector in 2016, of which $18 \%$ of annual household electricity use was for air conditioning. Residential electricity consumption seasonally rises and falls substantially more than commercial or industrial consumption, largely due to air conditioning use in the summer [6]. 
As the world's largest manufacturer and consumer of RACs, the total household electricity consumption in China in 2015 was up to 756.5 billion $\mathrm{kW} \cdot \mathrm{h}$; meanwhile, the production output of RACs (room air conditioners) has maintained a high growth rate since 1992, and up to 2015, it reached 142 million units [7]. In 2025, the total baseline electricity consumption of RACs will reach 753 billion $\mathrm{kW} \cdot \mathrm{h}$ [8]. Furthermore, the electricity consumption of RACs is estimated to account for $30 \%$ of the peak summer load in some large and medium-sized cities [9]. It can be expected that the potential of energy saving and greenhouse gas emissions reduction in RACs was much greater than in any other household electrical appliances in China [10]. Among the methods in effect, the standards and regulations issued by governmental or regional administration bureaus play a significant role in guiding and regulating the carbon emissions reduction expectation for RACs.

Besides the fundamental index of EER, more comprehensive and extensive methods for energy conservation have been introduced in RAC energy efficiency evaluation. The effect of the main external factors including room air temperature, defrosting behavior, and user interactions are analyzed on the energy consumption of existing refrigerating appliances in the home for more in depth analysis and a better understanding of the energy consumption of household refrigerators in different regions [11]. Thermodynamic perfectibility has been proposed as a consistent evaluation for the performance of RACs [12-15]. Life cycle cost analysis is widely applied to assess the impact of standard implementation to energy saving and emissions reduction in Europe [16]. By analyzing the relationship between life cycle reduction and energy efficiency improvement, the significance of energy efficiency evaluation is illustrated $[17,18]$. The rebound effect was added to find a rise in energy consumption after the implementation of the energy efficiency standard in China [19]. Recently, more scientists have recognized that the occupants' behavior has a significant effect on the energy consumption of their air-conditioner, and that thermal conditions also affect an occupant's behavior by influencing their expectation of thermal comfort [20-22]. Fundamental studies on the RAC performance national standard have mainly focused on the effectiveness of measurements in the test procedure $[23,24]$ and methods of lowering the uncertainty in theory [25-27].

To help the standards and regulations work more efficiently, researchers have carried out great work by applying these methods in standard revision. Additionally, many investigations have found that the stipulation and revision of RAC standards have been proven effective in reducing energy consumption and emissions. A scenario analysis focusing on residential RACs in Japan during 1972-2013 showed that for a reduction of an average lifetime of one year, if the air conditioner energy efficiency limit could be improved by $1.4 \%$ from the estimated current efficiency level, $\mathrm{CO}_{2}$ emissions could be reduced by approximately the same amount as for an extension of the average product lifetime of one year [28]. In Europe, the implementation of a minimum energy performance standard based on least life cycle costs could save up to $49 \mathrm{TWh}$ and $20 \mathrm{MtCO}_{2}$-eq in 2020. In the U.S., standards for RAC at efficiency level 3 revised by using common improvements found were more efficient and would save close to one quad of energy over 30 years and have a consumer NPV (net present value) between 0.14 billion and 1.82 billion dollars [29]. From 2005 to 2025, the energy efficiency standards for RACs in China could help save $1430-2540$ billion $\mathrm{kW} \cdot \mathrm{h}$ of electricity and reduce $908.3-1610.1 \mathrm{Mt} \mathrm{CO}_{2}$ emissions in different scenarios.

Among the electric appliances, China first issued the national standard on energy efficiency grades for RAC in 1989 [30]. With this initial edition, the Chinese national standard on RAC energy efficiency grades experienced three revisions in 2000 [31], 2004 [32], and 2010 [33] after learning from similar regulations made in the USA, European Union, and Japan [34-37]. Revisions in 2000 and 2004 both focused on upgrading energy efficiency threshold values, while the latest revision (2010) was upgraded by adjusting the previous five-class energy efficiency grading into a three-class energy efficiency grading for both constant and variable speed RACs. This new standard, which is currently in effect, obsoletes RACs with high energy consumption, therefore, it expects to meet the requirements for a global low-carbon city and the energy saving and emissions reduction policy in China [38,39]. 
However, in the case of the Chinese national standards, RAC energy efficiency evaluation has its roots in the Chinese national RAC performance standard [40]. In the RAC performance test, when D\&WBTs (dry-bulb and wet-bulb temperatures) change within their tolerances, respectively or simultaneously, the measured values of both CC (cooling capacity) and EER (energy efficiency ratio) of the unit are affected directly. For a particular unit, when values of CC measured in the performance test with different D\&WBTs happened to fall in two ranges of CC classified in the national standard, the values of the EER measured will label this unit with different energy efficiency classes (Table 1 as a reference). Concerning the fact that with the higher precision and accuracy of measurement instruments, D\&WBTs in the operation of the RAC performance test can now be kept much more stable than what they were 13 years ago, when the Chinese national RAC performance standard was put into effect and never revised thereafter. The lag in revising the D\&WBT tolerances set in the national RAC performance standard forms a sharp contrast to the continual revisions of the national RAC energy efficiency standard and calls for an effective method to reduce the uncertainty in obtaining true values of CC and EER of the test unit.

Table 1. Energy efficiency classification of constant frequency split RAC.

\begin{tabular}{|c|c|c|c|}
\hline \multirow{2}{*}{$\begin{array}{l}\text { The Rated Cooling } \\
\text { Capacity (CC) }\end{array}$} & \multicolumn{3}{|c|}{ EER $\left(W W^{-1}\right)$} \\
\hline & Class 1 & Class 2 & Class 3 \\
\hline $\mathrm{CC} \leq 4500 \mathrm{~W}$ & 3.60 & 3.40 & 3.20 \\
\hline $4500 \mathrm{~W}<\mathrm{CC} \leq 7100 \mathrm{~W}$ & 3.50 & 3.30 & 3.10 \\
\hline $7100 \mathrm{~W}<\mathrm{CC} \leq 14,000 \mathrm{~W}$ & 3.40 & 3.20 & 3.00 \\
\hline
\end{tabular}

In the Chinese national standard of RAC performance, D\&WBT tolerances refer to the maximum permissible deviations of specified D\&WBTs readings in RAC performance tests. For all other tests with the exception of the CC/heat pump test (e.g., defrosting test), the stipulated tolerances for both indoor and outdoor D\&WBTs are $\pm 1 / \pm 0.5^{\circ} \mathrm{C}$; for instantaneous readings in the CC/heat pump test, they are $\pm 0.5 / \pm 0.3{ }^{\circ} \mathrm{C}$; for average readings in the $\mathrm{CC} /$ heat pump test, they are $\pm 0.3 / \pm 0.2{ }^{\circ} \mathrm{C}$. Since the test results of CC and EER are the basis of energy efficiency evaluation, and changes of both indoor and outdoor D\&WBTs directly affect the test results of CC and EER, the method of tightening D\&WBT tolerances has been studied from various aspects. A formula for computing the wet-bulb temperature inversely from the relative humidity (or dewpoint temperature) and the air temperature has been proposed [41]. A method of non-linear classification of D\&WBT tolerances [42] and an algorithm for correcting D\&WBT tolerances using regression equations and analytic hierarchy process (AHP) [43] have also been proposed. In the successive study of weight analysis by using the core area and span ratio analysis [44] for tolerance correction, it was found that both indoor and outdoor D\&WBT tolerances should be studied respectively with due consideration.

\section{Principles of Tightening Instantaneous Indoor and Outdoor Dry-Bulb and Wet-Bulb Temperature Tolerances}

In GB/T 7725-2004 (Chinese national standard for room air conditioners) and GB/T 17758-2010 (Chinese national standard for unitary air conditioners), indoor and outdoor D\&WBT tolerances are specified specifically for each nominal working condition of constant and variable speed RAC. In particular, for variable speed RAC, nominal working conditions are more specifically defined with different running hours and operation load. For a precise energy efficiency evaluation, either indoor or outdoor D\&WBT tolerances are expected to be listed corresponding to each working condition.

The mathematical method proposed in this investigation can be applied to tighten indoor and outdoor D\&WBT tolerances for each working condition of both constant and variable speed RAC in regular performance tests. This process consists of RAC unit performance tests, data collection, mathematical calculation, and uncertainty evaluation. First, CC and PI (power input) are measured with indoor and outdoor D\&WBTs changing within the stipulated tolerances of $\pm 1 / \pm 0.5^{\circ} \mathrm{C}$, since 
even when D\&WBTs change within the tolerances, different working conditions of a RAC unit in testing results in different EER, and consequently leads to a discrepancy in energy efficiency evaluation. By using the air enthalpy method in RAC performance testing, finite discrete experimental data of CC and EER under specific working conditions can be obtained when indoor/outdoor D\&WBTs remain constant and outdoor/indoor D\&WBTs change within $\pm 1 / \pm 0.5^{\circ} \mathrm{C}$.

Second, based on the performance data, a series of mathematical calculation methods can be employed to tighten the instantaneous D\&WBT tolerances. Characteristics of the changes of CC and EER as the D\&WBTs change within the tolerances have been found. When analyzing and processing the discrete experimental data collected in a limited sample number, the AIC (Akaike information criterion) has frequently been applied in curve fitting and data prediction [45]. As a comprehensive index, the AIC evaluates the equations fitted by processing the sample size (n), the number of parameters (K), and the RSS (residual sum of squares), as is worked in Equation (1). The minimum AIC score is considered as the best evaluation criteria. When the finite sample size is comparatively small ( $\mathrm{n} / \mathrm{K}<<40)$, the AICc score (the corrected AIC score) can be employed, as in Equation (2) [46]. AICc has been widely applied in fitting curves of petrol price vs. macro-economy, energy consumption vs. year to their experimental data and $\mathrm{CO}_{2}$ emissions vs. energy consumption [47-49] and proves effective, but is not yet popular in processing experimental data in RAC unit tests. In this investigation, AICc was employed to achieve the best curve fitting and data prediction for CC and EER, respectively.

$$
\begin{aligned}
\mathrm{AIC} & =\mathrm{n} \times \ln \left(\frac{\mathrm{RSS}}{\mathrm{n}}\right)+2(\mathrm{~K}+1) \\
\mathrm{AIC} \mathrm{C} & =\mathrm{AIC}+\frac{2(\mathrm{~K}+1)(\mathrm{K}+2)}{\mathrm{n}-\mathrm{K}-2}
\end{aligned}
$$

Subsequently, considering the fact that the two independent variables of dry-bulb temperature and wet-bulb temperatures affect CC and EER simultaneously, 3D surfaces, instead of curves, that indicate the changes of CC and EER can be fitted respectively. Proper equation models can be chosen on the basis of the changing characteristics of CC and EER and applied in surface fitting. Typical models and their properties are listed in Appendix A. Using AICc, the best suitable equations are thus determined. Since non-uniform variation occurs in both CC and EER changing with indoor/outdoor D\&WBTs [50], the magnitudes of variation gradients of both CC and EER can be worked out in these most suitable equations. Furthermore, the narrowest intervals of CC and EER covering all extremal magnitudes of CC and EER gradients can be worked out, respectively, and are named as extremal intervals. In these two extremal intervals, the variation rates of $C C$ and EER reach the maximum, respectively. Considering the compound effect of CC and EER on tightening the D\&WBT tolerances, the union of D\&WBTs where both CC and EER have the maximum variation rates can be considered the tightened tolerances. When the D\&WBTs change within the tightened tolerances, CC and EER both fall in the intervals of gradient extrema. These tightened tolerances can make the measured CC and EER reflect their true values more convincingly, and eventually, a more accurate evaluation of energy efficiency can be realized.

According to the theory proposed above, constant speed RACs, for example, indoor and outdoor D\&WBT tolerances under refrigerating and heating working conditions, can be classified in 12 conditions, as shown in Figure 1, which presents in detail the tightening instantaneous indoor and outdoor D\&WBT tolerances of the sample unit $(7100 \mathrm{~W}<\mathrm{CC} \leq 14,000 \mathrm{~W})$ under the refrigerating working condition. 


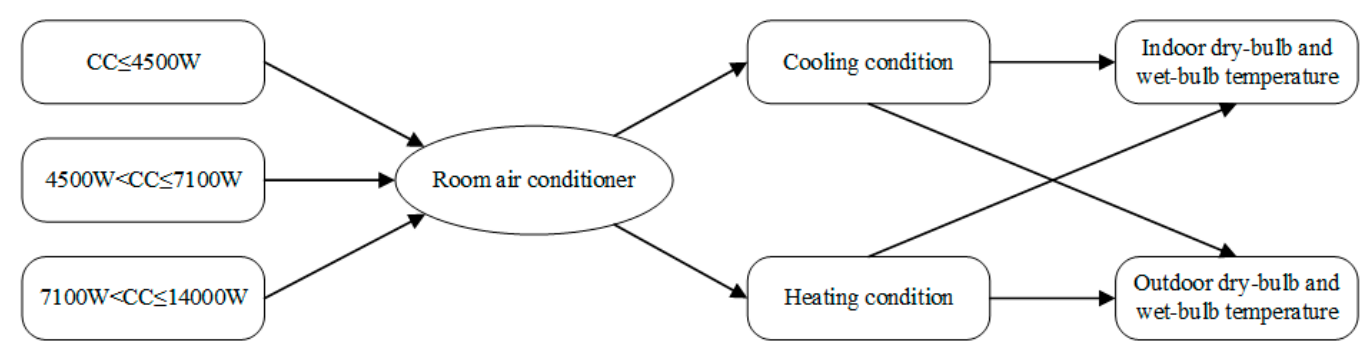

Figure 1. Diagram of the dry-bulb and wet-bulb temperature allowance classification.

\section{Case Study of Tightening D\&WBT Tolerances}

To make the procedure of tolerance-tightening clearer, instantaneous indoor and outdoor D\&WBT tolerances under the refrigerating working condition are described in detail below.

\subsection{Performance Experiment Setup and Testing}

A split type of a 12,500 W floor-standing room air conditioner of a well-known Chinese domestic brand (rated power at $12 \mathrm{~kW}$ and EER at $3.32 \mathrm{~kW} \cdot \mathrm{kW}^{-1}$ ) was chosen as the sample unit. R22, as the refrigerant fluid, was charged as per the requirement on the nameplate. Using the air enthalpy method, the performance tests were operated on this unit in an environmental lab accredited by the Chinese State Quality Supervision and Inspection Center on Compressors and Refrigerating Equipment (SQSICCRE). The test facility includes indoor and outdoor environment test rooms, the RAC unit, and the measuring instruments needed in the test. All the instruments and meters are calibrated in Chinese SQSICCRE and the accuracy meets the requirements of the national standard in China. Capacity of the test facility can meet the requirements of the sample unit performance test, and the precision of the testing facility is less than 2\% [51]. A YOKOGAWA PT100 Platinum resistance temperature sensor (type RS17-3NNNN-TB-L0120) with a measurement range of $0 \sim 70{ }^{\circ} \mathrm{C}$, precision at $\pm 0.1^{\circ} \mathrm{C}$, and uncertainty of error of indication at $0.041{ }^{\circ} \mathrm{C}$ was used.

In order to obtain comprehensive and complete (as far as possible) performance data for calculating both indoor and outdoor D\&WBT tolerances, the sample RAC unit performance tests consisted of two sections. Section A: when studying indoor D\&WBT tolerances, outdoor D\&WBTs were kept consistent at $35 / 24^{\circ} \mathrm{C}$, respectively with the widest variation of $\pm 0.02{ }^{\circ} \mathrm{C}$, and the widest variation of indoor D\&WBTs was kept within $\pm 1.0 / \pm 0.5^{\circ} \mathrm{C}$, respectively. Section B: when studying outdoor D\&WBT tolerances, indoor D\&WBTs were kept consistent at $27 / 19^{\circ} \mathrm{C}$, respectively, with the widest variation of $\pm 0.02{ }^{\circ} \mathrm{C}$, and the widest variation of outdoor D\&WBTs was kept within $\pm 1.0 / \pm 0.5{ }^{\circ} \mathrm{C}$, respectively. Meanwhile, in both sections, working conditions were set with both D\&WBTs changing with an equal step of $0.2{ }^{\circ} \mathrm{C}$ within $\pm 1.0 / \pm 0.5^{\circ} \mathrm{C}$. Nominal working conditions are included in the list of working conditions. The working conditions of the indoor and outdoor D\&WBTs in section A are listed in Table 2, and those in section B are listed in Table 3.

Table 2. Working conditions of the indoor and outdoor D\&WBTs changing within the tolerances: Section A.

\begin{tabular}{|c|c|c|c|c|c|c|c|c|c|c|c|}
\hline $\mathrm{WBT}^{\circ} \mathrm{C}$ & 26 & 26.2 & 26.4 & 26.6 & 26.8 & 27 & 27.2 & 27.4 & 27.6 & 27.8 & 28 \\
\hline 18.5 & 1\# & 2\# & 3\# & 4\# & 5\# & 6\# & 7\# & 8\# & 9\# & $10 \#$ & $11 \#$ \\
\hline 18.7 & 12\# & 13\# & $14 \#$ & 15\# & $16 \#$ & 17\# & 18\# & 19\# & 20\# & $21 \#$ & $22 \#$ \\
\hline 18.9 & 23\# & 24\# & 25\# & 26\# & $27 \#$ & 28\# & 29\# & 30\# & 31\# & $32 \#$ & 33\# \\
\hline 19 & 34\# & 35\# & 36\# & $37 \#$ & 38\# & 39\# & $40 \#$ & $41 \#$ & $42 \#$ & $43 \#$ & $44 \#$ \\
\hline 19.1 & 45\# & $46 \#$ & 47\# & $48 \#$ & 49\# & 50\# & 51\# & 52\# & 53\# & $54 \#$ & 55\# \\
\hline 19.3 & 56\# & $57 \#$ & $58 \#$ & 59\# & $60 \#$ & 61\# & 62\# & 63\# & 64\# & 65\# & 66\# \\
\hline 19.5 & $67 \#$ & 68\# & 69\# & 70\# & 71\# & 72\# & 73\# & 74\# & 75\# & 76\# & 77\# \\
\hline
\end{tabular}

Note: Refrigerating working condition with outdoor D\&WBTs kept at $35 / 24{ }^{\circ} \mathrm{C}$, and indoor D\&WBTs change within $\pm 1 / \pm 0.5^{\circ} \mathrm{C}$. Nominal working condition is in bold. 
Table 3. Working conditions of the indoor and outdoor D\&WBTs changing within the allowance: Section B.

\begin{tabular}{|c|c|c|c|c|c|c|c|c|c|c|c|}
\hline WBT ${ }^{\circ} \mathrm{C}$ & 34 & 34.2 & 34.4 & 34.6 & 34.8 & 35 & 35.2 & 35.4 & 35.6 & 35.8 & 36 \\
\hline 23.5 & 78\# & 79\# & 80\# & 81\# & 82\# & 83\# & $84 \#$ & 85\# & $86 \#$ & $87 \#$ & 88\# \\
\hline 23.7 & 89\# & 90\# & 91\# & 92\# & 93\# & 94\# & 95\# & 96\# & 97\# & 98\# & 99\# \\
\hline 23.9 & 100\# & 101\# & 102\# & 103\# & 104\# & 105\# & 106\# & $107 \#$ & 108\# & 109\# & 110\# \\
\hline 24 & 111\# & 112\# & 113\# & $114 \#$ & 115\# & 116\# & $117 \#$ & $118 \#$ & 119\# & 120\# & 121\# \\
\hline 24.1 & 122\# & 123\# & $124 \#$ & $125 \#$ & 126\# & 127\# & $128 \#$ & 129\# & 130\# & 131\# & 132\# \\
\hline 24.3 & 133\# & 134\# & 135\# & 136\# & 137\# & 138\# & 139\# & $140 \#$ & 141\# & 142\# & 143\# \\
\hline 24.5 & 144\# & 145\# & 146\# & $147 \#$ & 148\# & 149\# & 150\# & 151\# & 152\# & 153\# & 154\# \\
\hline
\end{tabular}

Note: Refrigerating working condition with indoor D\&WBTs kept at $27 / 19^{\circ} \mathrm{C}$, and outdoor D\&WBTs change within $\pm 1 / \pm 0.5^{\circ} \mathrm{C}$. Nominal working condition is in bold.

According to GB/T 7725-2004, when the performance test is proceeded with an expected stable working environment, the performance data are collected every seven seconds for 30 minutes. Automatically, the performance data collected fall into seven groups in chronological order and each group contributes its mean value as the data for record. Thus, the average of these seven records is considered as the final measured results of the performance data.

\subsection{Analysis of the Performance Test Results}

The measured results of CC and EER when outdoor or indoor D\&WBTs are kept consistent at $35 / 24{ }^{\circ} \mathrm{C}$ (Section A) or $27 / 19^{\circ} \mathrm{C}$ (Section B) are shown in Figures 2 and 3. In both Sections A and B, when the D\&WBT tolerances were tightened, the variation ranges of both CC and EER also narrowed down. $\triangle C C$ and $\triangle E E R$ are calculated to clarify the changes of CC and EER before and after D\&WBT tolerance tightening, as in Equations (3) and (4).

$$
\begin{gathered}
\Delta C C_{\max }=\frac{C C_{\max }-C C_{\min }}{\frac{1}{n} \sum_{i=1}^{n} C C_{T}} \\
\Delta E E R_{\max }=\frac{E E R_{\max }-E E R_{\min }}{\frac{1}{n} \sum_{i=1}^{n} E E R_{T}}
\end{gathered}
$$

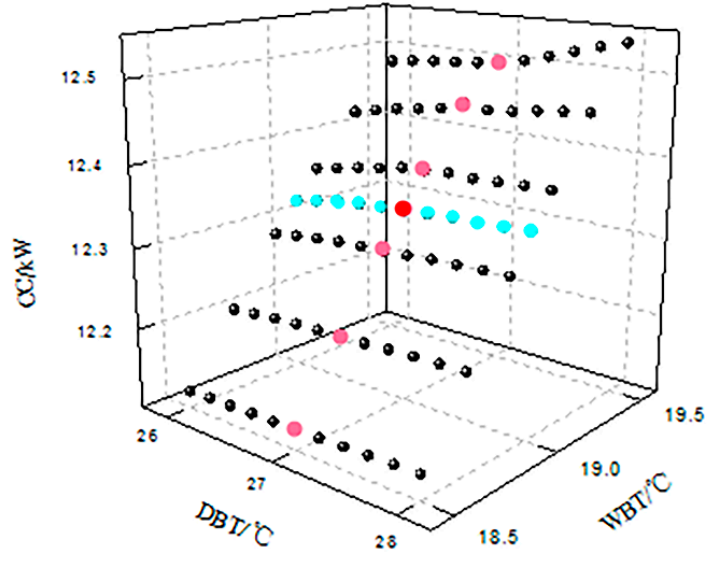

(a)

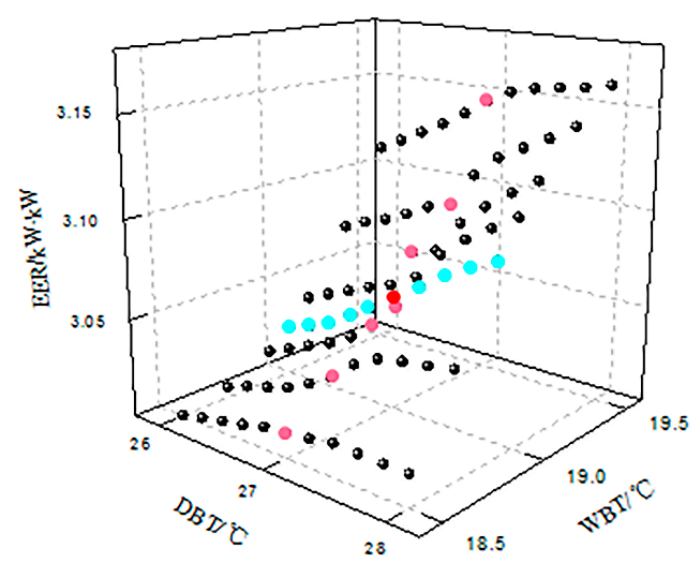

(b)

Figure 2. Measured results of cooling capacity $(C C, \mathbf{a})$ and energy efficiency ratio (EER, b) in Section A. 


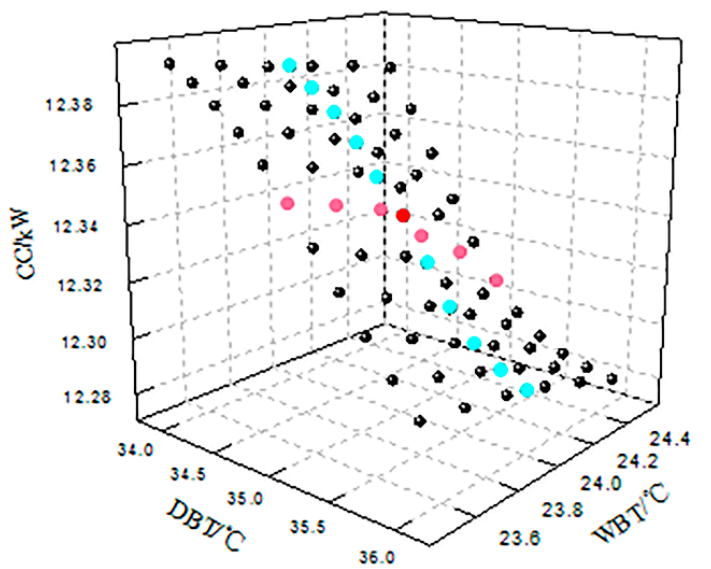

(a)

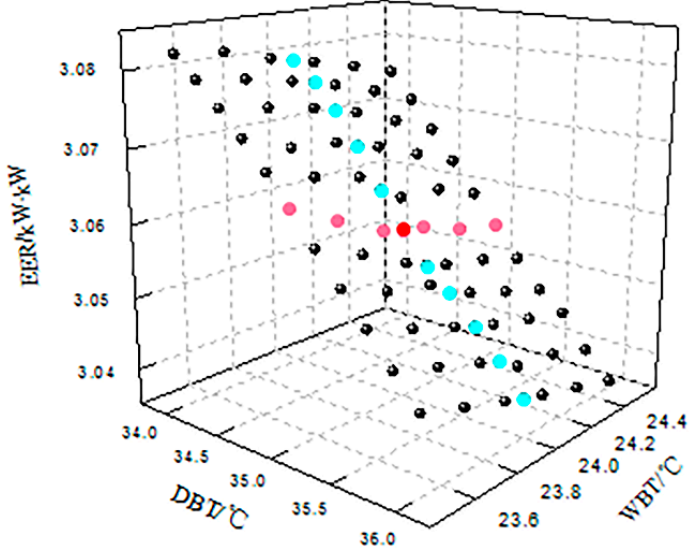

(b)

Figure 3. Measured results of CC (a) and EER (b) in Section B.

When the D\&WBTs changed simultaneously within the original tolerances of $\pm 0.5 / \pm 0.3{ }^{\circ} \mathrm{C}$, $\triangle C C_{\max 1}$ and $\triangle E E R_{\max 1}$ were calculated as $2.95 \%$ and $2.11 \%$, respectively. When they changed simultaneously within the tightened D\&WBT tolerances, $\Delta C C_{\max }$ and $\triangle E E R_{\max }$ were expected to be lower than those before tightening.

\section{Results and Discussion of the Case Study}

\subsection{Curve-Fitting and Equation-Determination for Cooling Capacity and Energy Efficiency Ratio}

Based on the experimental discretization results, the curves for CC and EER in Sections A and B were respectively fitted, as in Figures 4 and 5.

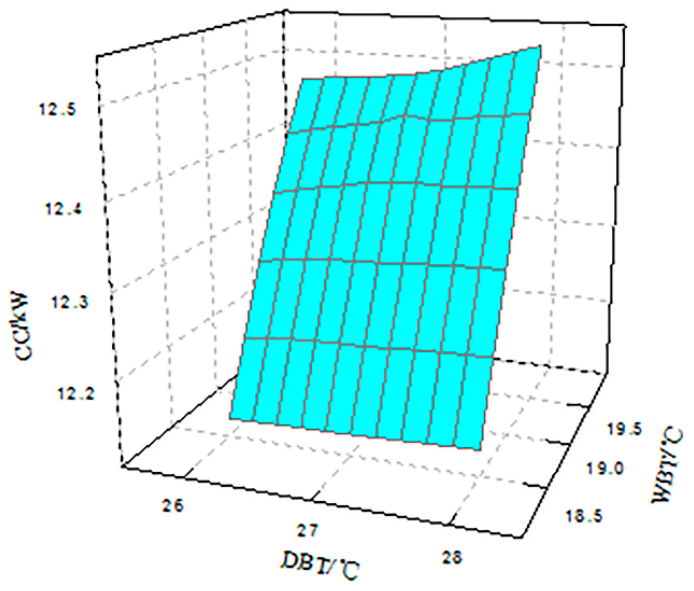

(a)

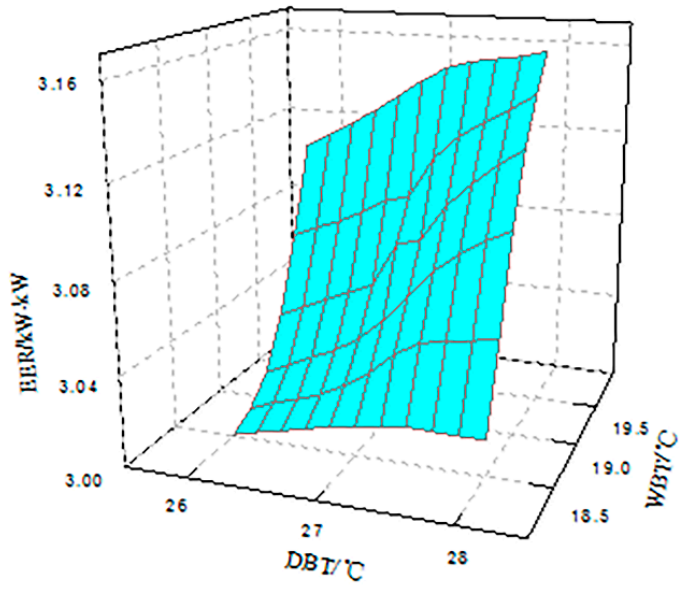

(b)

Figure 4. Relationship between CC and D\&WBT (a) and relationship between EER and D\&WBT (b) in Section A.

Figure 4 shows that CC and EER both increased gradually as the indoor D\&WBTs increased within the tolerances, and the gradients of both the CC and EER variation narrowed down after they widened in the first place. Figure 5 shows that CC and EER both decrease gradually as the outdoor D\&WBTs increase within the tolerances, and the gradients of both CC and EER variation showed the same tendency. According to the characteristics of CC and EER surfaces in two sections, eight equation models (ExtremeCum, GaussCum, Parabola2D, Rational2D, LogisticCum, Poly2D, Gauss2D, Lorentz2D) were chosen and applied in surface fitting. 


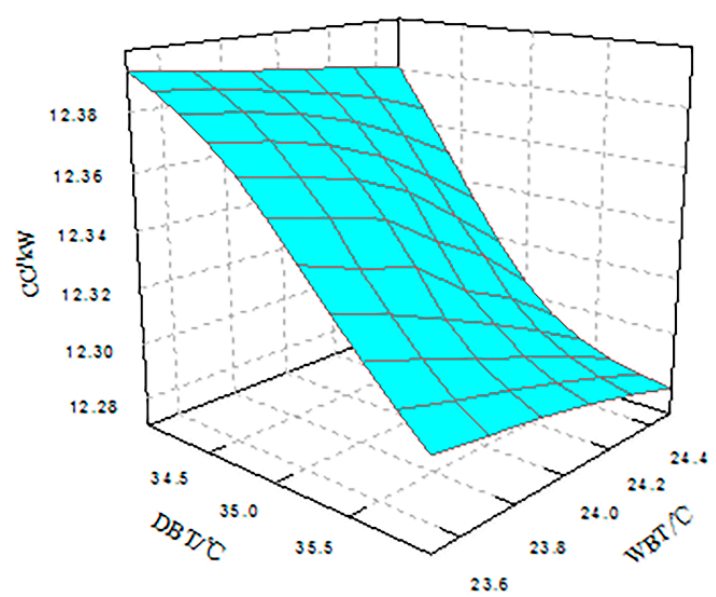

(a)

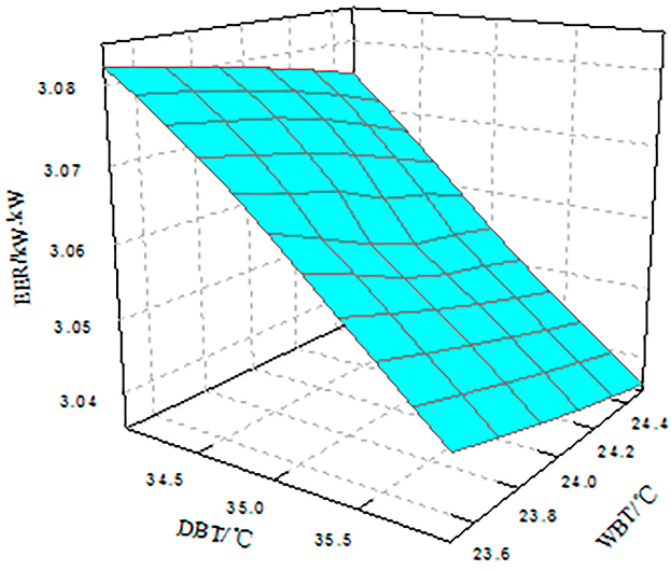

(b)

Figure 5. Relationship between CC and D\&WBT (a) and relationship between EER and D\&WBT (b) in Section B.

Learning from Table 4, which lists the values of n, K, RSS, AICc, and residual in these eight equation models, equations with the minimum AICc values were found and helped determine the most appropriate equations for surface-fitting. Among those eight equation models, ExtremeCum and GaussCum were found to be the best and were applied in fitting CC and EER surfaces in Section A, as in Equations (5) and (6); ExtremeCum and Lorentz2D were applied in fitting the surfaces in Section $\mathrm{B}$, as in Equations (7) and (8). The scores of the AICc and MAD (mean average differences) in these equations all reached the minimum. The mean fitted residuals of both CC and EER in the model were far less than $1 \%$, which meets the requirement of error controlling. The mathematical models can thus be considered as appropriate.

$$
\begin{gathered}
W=z_{1}+A_{1} \exp \left\{-\exp \left[\frac{D B T-B_{1}}{C 1}\right]\right\}+D_{1} \exp \left\{-\exp \left[\frac{W B T-E_{1}}{F_{1}}\right]\right\}+G_{1} \exp \left\{-\exp \left[\frac{D B T-B_{1}}{C_{1}}\right]-\exp \left[\frac{W B T-E_{1}}{F_{1}}\right]\right\} \\
E=E_{01}+0.25 a\left[1+\operatorname{erf}\left(\frac{x-b}{\sqrt{2} c}\right)\right]\left[1+\operatorname{erf}\left(\frac{y-d}{\sqrt{2} e}\right)\right] \\
W=z_{2}+A_{2} \exp \left\{-\exp \left[\frac{D B T-B_{2}}{C_{2}}\right]\right\}+D_{2} \exp \left\{-\exp \left[\frac{W B T-E_{2}}{F_{2}}\right]\right\}+G_{1} \exp \left\{-\exp \left[\frac{D B T-B_{2}}{C_{2}}\right]-\exp \left[\frac{W B T-E_{2}}{F_{2}}\right]\right\} \\
E=E_{02}+\frac{\mathrm{H}_{2}}{\left[1+\left(\frac{x-x_{c}}{w_{1}}\right)^{2}\right]\left[1+\left(\frac{x-y_{c}}{w_{2}}\right)^{2}\right]}
\end{gathered}
$$

The partial derivatives of Equations (5)-(8) with respect to the dry-bulb temperature and wet-bulb temperature were worked out respectively. Thus, the gradients of CC and EER changing with D\&WBTs were learnt: in Section A, the gradients of CC can be worked out with Equations (9) and (10) and the gradients of EER with Equations (11) and (12); in Section B, the gradients of CC can be worked out with Equations (13) and (14), and the gradients of EER with Equations (15) and (16). Parameters in all these equations and their standard errors are listed in Table 5.

$$
\begin{aligned}
& \operatorname{grad} D B T_{\mathrm{w}, \text { in }}=-\frac{1}{C_{1}} \exp \left(\frac{D B T-B_{1}}{C_{1}}\right)\left\{A_{1} \exp \left[-\exp \left(\frac{D B T-B_{1}}{C_{1}}\right)\right]+G_{1} \exp \left[-\exp \left(\frac{D B T-B_{1}}{C_{1}}\right)-\exp \left(\frac{W B T-E_{1}}{F_{1}}\right)\right]\right\} \\
& \operatorname{gradWBT_{\mathrm {w},\text {in}}}=-\frac{1}{F_{1}} \exp \left(\frac{W B T-E_{1}}{F_{1}}\right)\left\{D_{1} \exp \left[-\exp \left(\frac{W B T-E_{1}}{F_{1}}\right)\right]+G 1 \exp \left[-\exp \left(\frac{D B T-B_{1}}{C_{1}}\right)-\exp \left(\frac{W B T-E_{1}}{F_{1}}\right)\right]\right\} \\
& \operatorname{grad} D B T_{E, \text { in }}=\frac{a(D B T-d)}{2 c^{2}} \times \exp \left(\frac{D B T-b}{c}\right)^{2} \times\left[1+\int^{W B T} \exp \left(\frac{y-b}{e}\right)^{2} d y\right]
\end{aligned}
$$




$$
\begin{aligned}
& \operatorname{grad} W B T_{E, \text { in }}=\frac{a(W B T-d)}{2 e^{2}} \times \exp \left(\frac{W B T-b}{e}\right)^{2} \times\left[1+\int^{D B T} \exp \left(\frac{x-b}{c}\right)^{2} d x\right] \\
& \operatorname{grad} D B T_{W, \text { out }}=-\frac{1}{C_{2}} \exp \left(\frac{D B T-B_{2}}{C_{2}}\right) \times\left\{A_{2} \exp \left[-\exp \left(\frac{D B T-B_{2}}{C_{2}}\right)\right]+G_{2} \exp \left[-\exp \left(\frac{D B T-B_{2}}{C_{2}}\right)-\exp \left(\frac{W B T-E_{2}}{F_{2}}\right)\right]\right\} \\
& \operatorname{grad} W B T_{W, \text { out }}=-\frac{1}{F 2} \exp \left(\frac{W B T-E 2}{F 2}\right)\left\{D 2 \exp \left[-\exp \left(\frac{W B T-E 2}{F 2}\right)\right]+G 2 \exp \left[-\exp \left(\frac{D B T-B 2}{C 2}\right)-\exp \left(\frac{W B T-E 2}{F 2}\right)\right]\right\} \\
& \operatorname{grad} D B T_{E, \text { out }}=\frac{-2 \mathrm{H}_{2} x\left(x-x_{c}\right)}{w_{1}^{2}\left[1+\left(\frac{y-y_{c}}{w_{2}}\right)^{2}\right]^{2}\left[1+\left(\frac{x-x_{c}}{w_{1}}\right)^{2}\right]^{2}} \\
& \operatorname{grad} W B T_{E, \text { out }}=\frac{-2 \mathrm{H}_{2} y\left(y-y_{c}\right)}{w_{2}^{2}\left[1+\left(\frac{y-y_{c}}{w_{2}}\right)^{2}\right]^{2}\left[1+\left(\frac{x-x_{c}}{w_{1}}\right)^{2}\right]^{2}}
\end{aligned}
$$

\begin{tabular}{|c|c|c|c|c|c|c|}
\hline & & Surface Equation & $\mathrm{n}$ & $\mathbf{K}$ & RSS & AICc \\
\hline \multirow{8}{*}{ Section A } & \multirow{4}{*}{$\mathrm{CC}$} & ExtremeCum & 77 & 8 & $6.29 \times 10^{-4}$ & -881.3827 \\
\hline & & GaussCum & 77 & 6 & 0.00744 & -696.1695 \\
\hline & & Parabola2D & 77 & 5 & 0.00233 & -788.0383 \\
\hline & & Rational2D & 77 & 10 & $6.85 \times 10^{-4}$ & -869.4405 \\
\hline & \multirow{4}{*}{ EER } & GaussCum & 77 & 6 & 0.0046 & -733.2407 \\
\hline & & ExtremeCum & 77 & 8 & 0.00432 & -733.0129 \\
\hline & & LogisticCum & 77 & 6 & 0.00473 & -731.0947 \\
\hline & & Parabola2D & 77 & 5 & 0.00527 & -725.1938 \\
\hline \multirow{8}{*}{ Section B } & \multirow{4}{*}{$\mathrm{CC}$} & ExtremeCum & 77 & 8 & 0.0008 & -862.8657 \\
\hline & & Poly2D & 77 & 6 & 0.00104 & -847.727 \\
\hline & & LogisticCum & 77 & 6 & 0.00107 & -845.5372 \\
\hline & & Parabola2D & 77 & 5 & 0.00107 & -847.9605 \\
\hline & \multirow{4}{*}{ EER } & Lorentz2D & 77 & 6 & 0.00001 & -1205.3451 \\
\hline & & LogisticCum & 77 & 6 & 0.00041 & -919.4 \\
\hline & & Gauss2D & 77 & 6 & 0.00002 & -974.6737 \\
\hline & & Poly2D & 77 & 6 & 0.00002 & -1151.9728 \\
\hline
\end{tabular}

Table 4. Values of $\mathrm{n}$ (sample size), K (number of parameters), RSS (residual sum of squares), AICc (corrected Akaike information criterion) and residuals of CC (cooling capacity) and EER (energy Efficiency Ratio) curved surfaces in fitting equations.

* The bold equations are equations eventually employed in surface fitting.

Table 5. Parameters in the equations and corresponding standard errors.

\begin{tabular}{cccccc}
\hline & Section A & \multicolumn{3}{c}{ Section B } \\
\hline Coefficients & Values & Std. Err. & Coefficients & Values & Std. Err. \\
\hline $\mathrm{z}_{1}$ & 12.8838 & 0.28057 & $\mathrm{z}_{2}$ & 12.40618 & 1.55815 \\
$\mathrm{~A}_{1}$ & -1.12485 & 0.01812 & $\mathrm{~A}_{2}$ & -0.11316 & 0.07592 \\
$\mathrm{~B}_{1}$ & 3.28372 & 0.00206 & $\mathrm{~B}_{2}$ & 34.79658 & 0.05693 \\
$\mathrm{C}_{1}$ & 11.50367 & 0.37617 & $\mathrm{C}_{2}$ & 0.69338 & 0.00105 \\
$\mathrm{D}_{1}$ & -3.41898 & 0.09565 & $\mathrm{D}_{2}$ & -0.06099 & 0.00105 \\
$\mathrm{E}_{1}$ & 18.6476 & 0.04439 & $\mathrm{E}_{2}$ & 24.32344 & $7.45 \times 10^{-4}$ \\
$\mathrm{~F}_{1}$ & 0.67446 & 0.05232 & $\mathrm{~F}_{2}$ & 0.73729 & 0.00785 \\
$\mathrm{G}_{1}$ & 4.80125 & 0.64923 & $\mathrm{G}_{2}$ & -0.03284 & 0.01071 \\
$\mathrm{E}_{01}$ & 2.86422 & 0.05369 & $\mathrm{E}_{02}$ & 3.16174 & 25.11368 \\
$\mathrm{a}$ & 7.48386 & 30.7158 & $\mathrm{H}_{2}$ & -0.16117 & 0.98283 \\
$\mathrm{~b}$ & 28.09302 & 9.04607 & $\mathrm{x}_{\mathrm{c}}$ & 37.64974 & 0.91209 \\
$\mathrm{c}$ & 8.497602 & 6.05339 & $\mathrm{w}_{1}$ & 4.45582 & 20.04499 \\
$\mathrm{~d}$ & 23.75046 & 10.61517 & $\mathrm{y}_{\mathrm{c}}$ & 27.05263 & 4.50417 \\
$\mathrm{e}$ & 4.39005 & 2.9189 & $\mathrm{w}_{2}$ & 7.42034 & 1.25643 \\
\hline
\end{tabular}




\subsection{Calculation of Extrema Intervals of CC and EER}

In the working conditions listed in Tables 2 and 3, the controlling varieties method was employed to work out the extremal magnitudes of gradients in both curves of CC and EER. Furthermore, the extrema intervals of the CC/EER gradient were calculated. In Section A, the extrema interval of the CC gradient fell in the circle with the diameter of the dry-bulb temperature changing from 27.05 to $27.35^{\circ} \mathrm{C}$ and wet-bulb temperature from 19.18 to $18.86^{\circ} \mathrm{C}$, respectively; and the extrema interval of the EER gradient fell in the circle with the diameter of dry-bulb temperature changing from 27.03 to $26.78{ }^{\circ} \mathrm{C}$ and wet-bulb temperature from 18.94 to $19.14{ }^{\circ} \mathrm{C}$. In Section $\mathrm{B}$, the extrema interval of CC gradient fell in the circle with the diameter of the dry-bulb temperature changing from 35.03 to $35.45^{\circ} \mathrm{C}$ and the wet-bulb temperature from 23.89 to $24.28^{\circ} \mathrm{C}$, respectively. The extrema interval of the EER gradient fell in the circle with the diameter of the dry-bulb temperature changing from 35.09 to $34.65{ }^{\circ} \mathrm{C}$ and the wet-bulb temperature from 24.91 to $24.08^{\circ} \mathrm{C}$. As is shown in Figure 6 (a for Section A and $b$ for Section $B$ ), the intervals of the dry-bulb temperature and wet-bulb temperature in both cases only partly overlapped, which also numerically illustrates that the gradients of CC and EER were not exactly in accord with each other.

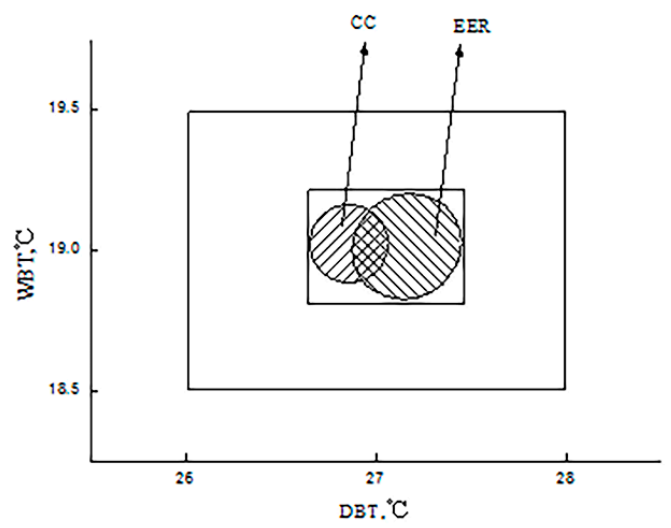

(a)

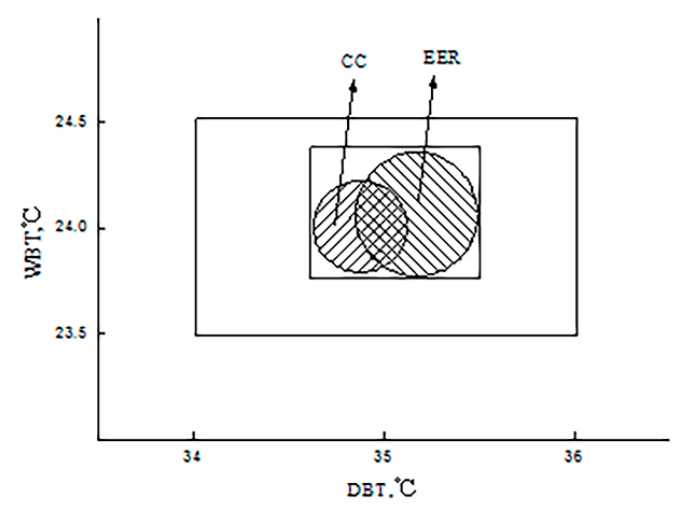

(b)

Figure 6. Extrema intervals of CC and EER and the tightening of D\&WBT tolerances. (a) Section A; (b) Section B.

It was found that increasing rates of CC and EER gradients were positive when the D\&WBTs were below the minimal extremum, (that is, the variation rates of CC and EER both increased). The increasing rates of CC and EER were zero when the D\&WBTs changed within the extrema intervals, (that is, the variation rates of $C C$ and EER both remained consistent). The increasing rates of CC and EER were negative when the D\&WBTs were beyond the maximal extremum, (that is, variation rates of CC and EER both decreased). It can be concluded that the variation rates of CC and EER both reached the peak when the D\&WBTs changed within their extrema intervals. Therefore, in the RAC unit performance test, tests with D\&WBTs changing within the extrema intervals should be more intense.

\subsection{The Tightened Results of Indoor and Outdoor DEWBT Tolerances}

Considering the feasibility, the tightened tolerances of D\&WBTs were defined as the rectangular worked out with the minimal and maximal values of D\&WBTs in the union of gradient extrema intervals of CC and EER. The tightened indoor dry-bulb temperature tolerance was calculated as 26.7 27. ${ }^{\circ} \mathrm{C}$ and the wet-bulb temperature was $18.8 \sim 19.2^{\circ} \mathrm{C}$, respectively. In the tightened tolerances, $\triangle \mathrm{CC}_{\max }$ and $\triangle \mathrm{EER}_{\max }$ were yielded as $1.40 \%$ and $1.03 \%$. The tightened outdoor dry-bulb temperature tolerances were calculated as $26.6 \sim 27.4{ }^{\circ} \mathrm{C}$ and the wet-bulb temperature was $18.7 \sim 19.3^{\circ} \mathrm{C}$, respectively, when $\triangle \mathrm{CC}_{\max }$ and $\triangle \mathrm{EER}_{\max }$ were $1.62 \%$ and $1.25 \%$, respectively. In the Chinese national standard currently in effect, both indoor and outdoor D\&WBT tolerances specified for cooling capacity test and 
heat pump test were $26.5 \sim 27.5^{\circ} \mathrm{C}$ and $18.7 \sim 19.3^{\circ} \mathrm{C}$, respectively, when $\Delta \mathrm{CC}_{\max }$ and $\Delta \mathrm{EER}$ max were $2.95 \%$ and $2.11 \%$. Comparisons of indoor and outdoor D\&WBT tolerances before and after tightening and the corresponding $\Delta \mathrm{CC}_{\max }$ and $\triangle \mathrm{EER}_{\max }$ are shown in Table 6.

Table 6. D\&WBT tolerances and the corresponding $\triangle \mathrm{CC}_{\max }$ and $\triangle \mathrm{EER}_{\max }$ before and after tightening.

\begin{tabular}{ccccc}
\hline \multirow{2}{*}{ Tolerances } & \multicolumn{4}{c}{ Range } \\
\cline { 2 - 5 } & DBT ${ }^{\circ} \mathbf{C}$ & WBT $^{\circ} \mathbf{C}$ & $\mathbf{\Delta C C}_{\text {max }}$ & EEER $_{\text {max }}$ \\
\hline Indoor tolerances before tightening & $26.5 \sim 27.5$ & $18.7 \sim 19.3$ & $2.95 \%$ & $2.11 \%$ \\
Outdoor tolerances before tightening & $26.5 \sim 27.5$ & $18.7 \sim 19.3$ & $2.95 \%$ & $2.11 \%$ \\
Indoor tolerances after tightening & $26.7 \sim 27.3$ & $18.8 \sim 19.2$ & $1.40 \%$ & $1.03 \%$ \\
Outdoor tolerances after tightening & $26.6 \sim 27.4$ & $18.7 \sim 19.3$ & $1.62 \%$ & $1.25 \%$ \\
\hline
\end{tabular}

With the nominal working condition at the center, the indoor and outdoor D\&WBT tolerances were narrowed into $\pm 0.3 / \pm 0.2{ }^{\circ} \mathrm{C}$ and $\pm 0.4 / \pm 0.3{ }^{\circ} \mathrm{C}$. The lowering of $\Delta \mathrm{CC}_{\max }$ and $\Delta \mathrm{EER}_{\max }$ indicates the possibility of the measured $\mathrm{CC}$ in the nominal working condition being convincingly considered as has been improved by $18 \%$, and that of the measured EER by $48 \%$.

Meanwhile, the investigation results showed that the indoor and outdoor D\&WBTs did not necessarily have to change within the same tolerances, as they are required to in the current Chinese national standard. Considering the fact that the indoor D\&WBTs affect the inlet air enthalpy values of the RAC directly, they affect the CC and EER test results more than that of the outdoor D\&WBTs. It is safe to conclude that the pattern of narrower indoor D\&WBT tolerances accompanying comparatively wider outdoor D\&WBT tolerances can be more appropriate in determining CC and EER test results for energy efficiency evaluation.

\subsection{Analysis of Uncertainty in CC/EER Measurement}

By applying the calculation method for uncertainty [52], the measurement accuracy and the standard uncertainty for pressure, temperature, and power input are listed in Table 7. The enthalpy uncertainty is determined by D\&WBTs and atmospheric pressure, thus the enthalpy uncertainties of the inlet air and outlet air at the indoor side can be calculated using Equations (17) and (18):

$$
\begin{aligned}
& u^{2}\left(h_{a 1}\right)=\left(\frac{\partial \varphi}{\partial t_{d 1}} u\left(t_{d 1}\right)\right)^{2}+\left(\frac{\partial \varphi}{\partial t_{w 1}} u\left(t_{w 1}\right)\right)^{2}+\left(\frac{\partial \varphi}{\partial p_{0}} u\left(p_{0}\right)\right)^{2} \\
& u^{2}\left(h_{a 2}\right)=\left(\frac{\partial \varphi}{\partial t_{d 2}} u\left(t_{d 2}\right)\right)^{2}+\left(\frac{\partial \varphi}{\partial t_{w 2}} u\left(t_{w 2}\right)\right)^{2}+\left(\frac{\partial \varphi}{\partial p_{0}} u\left(p_{0}\right)\right)^{2}
\end{aligned}
$$

Table 7. Measured accuracy and uncertainty.

\begin{tabular}{cccc}
\hline Measurement & Unit & Accuracy & Uncertainty \\
\hline Platinum resistance temperature sensor & ${ }^{\circ} \mathrm{C}$ & $\pm 0.1{ }^{\circ} \mathrm{C}$ & $0.058^{\circ} \mathrm{C}$ \\
Pressure sensor & $\mathrm{MPa}$ & $\pm 0.25 \%$ & $0.14 \mathrm{MPa}$ \\
Pressure differential sensor & $\mathrm{MPa}$ & $0.50 \%$ & $0.00072 \mathrm{MPa}$ \\
Power input & $\mathrm{W}$ & $0.1 \%$ & $1.96 \mathrm{~W}$ \\
\hline
\end{tabular}

Thus, the enthalpy uncertainties of the inlet air and outlet air were 32.4 and 31.2, respectively.

The Type A evaluation, Type B evaluation, and combined standard uncertainty were calculated and are listed in Table 8. 
Table 8. Evaluation of uncertainty for CC and EER measurements.

\begin{tabular}{ccccc}
\hline \multirow{2}{*}{ Evaluation of Uncertainty } & \multicolumn{2}{c}{ Outdoor Side } & \multicolumn{2}{c}{ Indoor Side } \\
\cline { 2 - 5 } & CC & EER & CC & EER \\
\hline Type A evaluation of uncertainty & 0.003987545 & 0.001474566 & 0.01386677 & 0.004627448 \\
Type B evaluation of uncertainty & 0.008373845 & 0.008847394 & 0.04546482 & 0.029868073 \\
Combined standard uncertainty & $0.927 \%$ & $0.897 \%$ & $4.753 \%$ & $3.022 \%$ \\
\hline
\end{tabular}

\section{Conclusions}

Theoretically speaking, when the D\&WBT tolerances are narrowed, the variation rates of CC and EER in the performance tests can be effectively decreased, and the reliability of the energy efficiency class determination can be more convincing. To accommodate the development of a global low-carbon economy, the continuous upgrading of the threshold values of RAC energy efficiency grades raise the requirements in RAC performance. Correspondingly, RAC performance test reliability is in need of improvement to avoid possible mis-evaluation of energy efficiency caused by measurements as much as possible.

Technically speaking, the instantaneous indoor and outdoor D\&WBT tolerances proposed herein aim at avoiding "bad money drives out goo" in the RAC market in China. Current tolerances leave a generous range for CC and EER measurement. With the measuring instruments of greatly improved accuracy and precision than a decade ago, when the currently enacted national RAC performance standard was put into effect, the D\&WBTs in performance test operation can be manipulated to fall into the energy efficiency class expected. For instance, by controlling the D\&WBTs or experimental coincident, a RAC unit that actually fails to reach Class 3 can be labeled as Class 3, and a unit actually qualified for Class 3 can be determined as unqualified. Out of financial concern, products of the quality "in the margin" may gradually drive out those truly qualified units, and units of higher energy-consuming may gradually drive out those comparatively energy-saving units. RAC of energy efficiency Class 3 is of more significance in energy-saving in China because RAC units of low energy efficiency, currently being more popular in the household RAC market, have turned out to be massive energy-consuming object. When "bad money drives out good" in the household RAC market, this will end up with a massive energy waste. A responsible revision of the current Chinese national RAC performance standard will noticeably contribute to preventing unhealthy and unfair evaluations from happening.

Additionally, it has to be mentioned that the tightened D\&WBT tolerances worked out in this investigation were only the calculation results for one particular RAC unit with a certain rated cooling capacity. Determination of D\&WBT tolerances for this type of RAC can be achieved on the basis of greater performance test data and further data analysis. Furthermore, the determination of indoor and outdoor D\&WBT tolerances for average readings in cooling capacity and heat pump tests under different working conditions of both constant and variable speed RAC units with different rated cooling capacity requires further theoretical research and much greater experimental analysis.

Furthermore, consumers can expect more reliable energy efficiency and electricity savings of energy appliance products with a revised energy efficiency evaluation using precise D\&WBT tolerances. With the expected sales of RAC in China between 2009 and 2020 being about 500 million units [53], the energy saving and reduction in carbon emissions can be noticeably large, especially in summer when the energy demand amounts normally peak during the year.

Author Contributions: Formal analysis, D.C. and X.H.; Funding acquisition, Z.Z.; Investigation, X.H.; Methodology, Z.Z.; Resources, Z.Z.; Software, D.C.; Writing—original draft, X.H.; Writing—review \& editing, X.H. All authors have read and agreed to the published version of the manuscript.

Funding: This research was supported by the Postgraduate Research \& Practice Innovation Program of Jiangsu Province, China (SJKY19_1182), the Excellent Graduate Workshop in Nanfeng Cold-Chain Co. Ltd., and the Excellent Graduate Workshop in Jiangsu Beiyang Cold-Chain Equipment Technology Co. Ltd. in Jiangsu Province, China, and the Key Research and Development Project in Zhenjiang, China (GY2019025). 
Conflicts of Interest: The authors declare no conflicts of interest. The founding sponsors had no role in the design of the study; in the collection, analyses, or interpretation of data; in the writing of the manuscript, and in the decision to publish the results.

\section{Abbreviations}

$\begin{array}{ll}\text { CC } & \text { Cooling Capacity } \\ \text { EER } & \text { Energy Efficiency Ratio } \\ \text { DBT } & \text { Dry Bulb Temperature } \\ \text { WBT } & \text { Wet Bulb Temperature } \\ \text { D\&WBTs } & \text { Dry and Wet Bulb Temperatures } \\ \text { RAC } & \text { Room air conditioner } \\ \text { PI } & \text { Power input } \\ \text { AIC } & \text { Akaike information criterion } \\ \text { AICc } & \text { Corrected Akaike information criterion } \\ \text { RSS } & \text { Residual sum of squares } \\ \text { MAD } & \text { Mean average differences } \\ \text { SQSICCRE } & \text { State Quality Supervision and Inspection Center on Compress } \\ \text { Nomenclature } & \\ \mathrm{i}=1 & \text { Working condition of variable DBT } \\ \mathrm{i}=2 & \text { Working condition of variable WBT } \\ \mathrm{i}=3 & \text { working condition of coupling variation between D\&WBT } \\ \mathrm{n} & \text { sample size } \\ \mathrm{K} & \text { number of parameters } \\ \mathrm{CC}_{\max } & \text { maximum of cooling capacity }(\mathrm{W}) \\ \mathrm{EER}_{\max } & \text { maximum of EER } \\ \Delta C \mathrm{C}_{\text {max }} & \text { gradient of cooling capacity maximum }(\mathrm{W}) \\ \Delta \mathrm{EER}_{\text {max }} & \text { gradient of EER maximum } \\ \mathrm{CC}_{\mathrm{T}} & \text { tightened of cooling capacity }(\mathrm{W}) \\ \mathrm{EER}_{\mathrm{T}} & \text { tightened of EER } \\ \mathrm{h}_{\mathrm{a} 1} & \text { enthalpy of inlet air at indoor side }(\mathrm{J} / \mathrm{kg}) \\ \mathrm{h}_{\mathrm{a} 2} & \text { enthalpy of outlet air at indoor side }(\mathrm{J} / \mathrm{kg}) \\ \mathrm{t}_{\mathrm{d} 1} & \text { dry-bulb temperature of inlet air }\left({ }^{\circ} \mathrm{C}\right) \\ \mathrm{t}_{\mathrm{d} 2} & \text { dry-bulb temperature of outlet air }\left({ }^{\circ} \mathrm{C}\right) \\ \mathrm{t}_{\mathrm{w} 1} & \text { wet-bulb temperature of inlet air }\left({ }^{\circ} \mathrm{C}\right) \\ \mathrm{t}_{\mathrm{w} 2} & \text { wet-bulb temperature of outlet air }\left({ }^{\circ} \mathrm{C}\right) \\ \mathrm{P}_{0} & \text { atmospheric pressure }(\text { Pa) } \\ & \end{array}$

\section{Appendix A}

Table A1. Typical models and their properties.

\begin{tabular}{ll}
\hline Surface Type & Equation \\
\hline ExtremeCum & $z=z_{c}+B \exp \left[-\exp \left(\frac{C-x}{D}\right)\right]+E \exp \left[-\exp \left(\frac{F-y}{G}\right)\right]+H \exp \left[-\exp \left(\frac{C-x}{D}\right)-\exp \left(\frac{F-y}{G}\right)\right]$ \\
\hline Poly2D & $z=z_{c}+A x+B y+C x^{2}+D y^{2}+F x y$ \\
\hline LogisticCum & $z=z_{c}+\frac{B}{\left[1+\exp \left(\frac{C-x}{D}\right)\right]\left[1+\exp \left(\frac{E-x}{F}\right)\right]}$ \\
\hline Parabola2D & $z=z_{c}+A x+B y+C x^{2}+D y^{2}$ \\
\hline Gauss2D & $z=z_{c}+A \exp \left[-\frac{1}{2}\left(\frac{x-x_{c}}{w_{1}}\right)^{2}-\frac{1}{2}\left(\frac{y-y_{c}}{w_{2}}\right)^{2}\right]$ \\
\hline
\end{tabular}


Table A1. Cont.

\begin{tabular}{ll}
\hline Surface Type & Equation \\
\hline Lorentz2D & $z=z_{c}+\frac{A}{\left[1+\left(\frac{x-x_{c}}{w_{1}}\right)^{2}\right]\left[1+\left(\frac{y-y_{c}}{w_{2}}\right)^{2}\right]}$ \\
\hline GaussCum & $z=z_{c}+0.25 B\left[1+\operatorname{erf}\left(\frac{x-C}{\sqrt{2} D}\right)\right]\left[1+\operatorname{erf}\left(\frac{y-E}{\sqrt{2} F}\right)\right]$ \\
\hline Rational2D & $z=\frac{z_{c}+A_{01} x+B_{01} y+B_{02} y^{2}+B_{03} y^{2}}{1+A_{1} x+A_{2} x^{2}+A_{3} x^{3}+B_{1} y+B_{2} y^{2}}$ \\
\hline
\end{tabular}

Remarks: $\mathrm{z}_{\mathrm{C}}, \mathrm{x}_{\mathrm{c}}, \mathrm{y}_{\mathrm{c}}, w_{1}, w_{2}, A, B, C, D, E$, and $F$ are constants/coefficients; $\mathrm{x}$ and $\mathrm{y}$ are independent variable; and $\mathrm{z}$ is a dependent variable.

\section{References}

1. Rogelj, J.; Fricko, O.; Meinshausen, M.; Krey, V.; Zilliacus, J.J.J.; Riahi, K. Understanding the origin of Paris Agreement emission uncertainties. Nature Commun. 2017. [CrossRef] [PubMed]

2. Borg, S.P.; Kelly, N.J. The effect of appliance energy efficiency improvements on domestic electric loads in European households. Energy Build. 2011, 43, 2240-2250. [CrossRef]

3. Nishijima, D. The role of technology, product lifetime, and energy efficiency in climate mitigation: A case study of air conditioners in Japan. Energy Policy 2017, 104, 340-347. [CrossRef]

4. The Japan Refrigeration and Air Conditioning Industry Association. World Air Conditioner Demand by Region; JRAIA: Tokyo, Japan, 2017.

5. Statistics Bureau of Japan. Japan Statistical Yearbook 2017; SBJ: Tokyo, Japan, 2017.

6. US Energy Information Administration. Annual Energy Outlook; EIA: Washington, DC, USA, 2017.

7. National Bureau of Statistics of China. China Statistical Yearbook 2016; NBSC: Beijing, China, 2016.

8. Yu, H.; Tang, B.J.; Yuan, X.C.; Wang, S.; Wei, Y.M. How do the appliance energy standards work in China? Evidence from room air conditioners. Energy Build. 2015, 86, 833-840. [CrossRef]

9. Yu, S.; Wei, Y.M.; Wang, K. China's primary energy demands in 2020: Predictions from an MPSO-RBF estimation model. Energy Convers. Manag. 2012, 61,59-66. [CrossRef]

10. Zhou, N.; Fridley, D.; McNeil, M.; Zheng, N.; Letschert, V.; Ke, J.; Saheb, Y. Analysis of potential energy saving and CO2, emission reduction of home appliances and commercial equipments in China. Energy Policy 2011, 39, 4541-4550. [CrossRef]

11. Harrington, L.; Aye, L.; Fuller, R.J. Opening the door on refrigerator energy consumption: Quantifying the key drivers in the home. Energy Effic. 2018, 11, 1519-1539. [CrossRef]

12. Tian, H.; Ma, Y.T.; Li, M.X.; Liu, C.T.; Zhao, L. The status and development trend of the water chiller energy efficiency standard in China. Energy Policy 2010, 38, 7497-7503.

13. Yuan, Q.X.; Ma, Y.T.; Liu, C.T.; Dai, B.M.; Yan, Q.H. Thermodynamic perfectibility based analysis of energy-efficiency standards for air conditioning products in China. Energy Build. 2011, 43, 3627-3634. [CrossRef]

14. Ma, Y.T.; Tian, H.; Liu, C.T.; Yuan, Q.X. Analysis on Energy Efficiency Standards and Thermodynamic Perfectibility for Products of Refrigeration and Heat Pump. J. Refrig. 2012, 33, 1-6.

15. Li, X.F.; Ma, Y.T.; Yan, Q.H. Analysis on thermodynamic perfectibility of room air conditioners. J. Refrig. 2013, 34, 18-23.

16. Grignon-Masse, L.; Rivière, P.; Adnot, J. Strategies for reducing the environmental impacts of room air conditioners in Europe. Energy Policy 2011, 39, 2152-2164. [CrossRef]

17. Vendrusculo, E.A.; de Castilho Queiroz, G.; Jannuzzi, G.D.M.; da Silva Júnior, H.X.; Pomilio, J.A. Life cycle cost analysis of energy efficiency design options for refrigerators in Brazil. Energy Effic. 2009, 2, 271-286. [CrossRef]

18. Shi, X. Setting effective mandatory energy efficiency standards and labelling regulations: A review of best practices in the Asia Pacific region. Appl. Energy 2014, 133, 135-143. [CrossRef]

19. Liu, J.; Sun, X.; Lu, B.; Zhang, Y.; Sun, R. The life cycle rebound effect of air-conditioner consumption in China. Appl. Energy 2016, 184, 1026-1032. [CrossRef] 
20. Schweiker, M. Study on the effect of preference of Air-Conditioning usage on the exergy consumption pattern within a built environment. Int. J. Exergy 2012, 11, 409-422. [CrossRef]

21. Ren, X.; Yan, D.; Wang, C. Air-conditioning usage conditional probability model for residential buildings. Build. Environ. 2014, 81, 172-182. [CrossRef]

22. Wu, J.; Liu, C.; Li, H.; Ouyang, D.; Cheng, J.; Wang, Y.; You, S. Residential air-conditioner usage in China and efficiency standardization. Energy 2016, 119, 1036-1046. [CrossRef]

23. Wang, Z.Y.; Xu, Z.L. Air Conditioner Performance Testing; Science Press: Beijing, China, 2009.

24. Mahlia, T.M.I.; Saidur, R. A review on test procedure, energy efficiency standards and energy labels for room air conditioners and refrigerator-freezers. Renew. Sust. Energ. Rev. 2010, 14, 1888-1900. [CrossRef]

25. Zhang, K.; Zhang, X.S.; Chen, X.Y. Analysis on Uncertainty in Testing of Air Conditioner by Means of Air Enthalpy Method. Fluid Mach. 2006, 34, 72-75.

26. Diaz, N.F. Methodology for uncertainty calculation of net total cooling effect estimation for rating room air conditioners and packaged terminal air conditioners. Int. J. Refrig. 2009, 32, 1472-1477. [CrossRef]

27. Jiang, M.L.; Mao, X.C.; Yu, G.R. Research on evaluating the uncertainty of cooling capacity for air conditioners using air- enthalpy method. Cryog. Supercond. 2011, 39, 36-40.

28. Nishijima, D. Product lifetime, energy efficiency and climate change: A case study of air conditioners in Japan. J. Environ. Manag. 2016, 181, 582-589. [CrossRef] [PubMed]

29. Lekov, A.B.; Franco, V.H.; Meyers, S. Evaluation of energy-efficiency standards for room air conditioners in the US. Open J. Energy Effic. 2012, 12, 9-20. [CrossRef]

30. General Administration of Quality Supervision, Inspection and Quarantine of the PRC \& Standardization Administration of the PRC. The Minimum Allowable Values of the Energy Efficiency and Energy Efficiency Grades for Room Air Conditioners; GB/T 12021.3-1989; International Energy Agency: Paris, France, 1989.

31. General Administration of Quality Supervision, Inspection and Quarantine of the PRC \& Standardization Administration of the PRC. The Minimum Allowable Values of the Energy Efficiency and Energy Efficiency Grades for Room Air Conditioners; GB/T 12021.3-2000; International Energy Agency: Paris, France, 2000.

32. General Administration of Quality Supervision, Inspection and Quarantine of the PRC \& Standardization Administration of the PRC. The Minimum Allowable Values of the Energy Efficiency and Energy Efficiency Grades for Room Air Conditioners; GB 12021.3-2004; International Energy Agency: Paris, France, 2004.

33. General Administration of Quality Supervision, Inspection and Quarantine of the PRC \& Standardization Administration of the PRC. The Minimum Allowable Values of the Energy Efficiency and Energy Efficiency Grades for Room Air Conditioners; GB/T 12021.3-2010; International Energy Agency: Paris, France, 2010.

34. US Department of Energy. Energy Conservation Program: Energy Conservation Standards for Residential Clothes Dryers and Room Air Conditioners: Final Rule; Federal Registar: Washington, DC, USA, 2011.

35. The Japan Refrigeration and Air Conditioning Industry Association. Calculating Method of Annual Power Consumption for Room Air Conditioners JRA 4046; JRAIA: Tokyo, Japan, 2005.

36. European Commission. G/TBT/N/EEC/362 of the European Parliament and of the Council with Regard to Eco-Design Requirements for Air Conditioners and Comfort Fans; European Commission: Brussels, Belgium, 2011.

37. European Commission. G/TBT/N/EEC/363 of the European Parliament and of the Council with Regard to Energy Labeling of Air Conditioners; European Commission: Brussels, Belgium, 2011.

38. Lu, W. Potential energy savings and environmental impacts of energy efficiency standards for vapor compression central air conditioning units in China. Energy Policy 2007, 35, 1709-1717. [CrossRef]

39. Khanna, N.Z.; Zhou, N.; Fridley, D.; Fino-Chen, C. Evaluation of China's local enforcement of energy efficiency standards and labeling programs for appliances and equipment. Energy Policy 2013, 63, 646-655. [CrossRef]

40. General Administration of Quality Supervision, Inspection and Quarantine of the PRC; Standardization Administration of the PRC. Room Air Conditioners GB/T 7725-2004; General Administration of Quality Supervision, Inspection and Quarantine of the PRC: Beijing, China, 2004.

41. Lee, C.; Wang, Y.J. A Novel Method to Derive Formulas for Computing the Wet-Bulb Temperature from Relative Humidity and Air Temperature. Measurement 2018, 128, 271-275. [CrossRef]

42. Zhang, Z.B.; Du, K.; Huang, H.; Zhang, R.N. Grading of dry-bulb and wet-bulb temperature allowances based on characteristics of performance curves. Chin. J. Mech. Eng. 2014, 50, 157-162. [CrossRef]

43. Zhang, Z.B.; Du, K.; Huang, H.; Zhang, R.N. Dry-bulb and wet-bulb temperature allowances grading based on the characteristics of performance curves. J. Chem. Ind. Eng. 2014, 65, 3676-3679. 
44. Zhang, Z.B.; Huang, H.; Li, Y.L.; Huang, Y.A. Mathematical correction based on weight analysis on instantaneous dry-bulb and wet-bulb temperatures tolerances specified for cooling capacity test and heat pump test. Sci. Technol. Built Environ. 2016, 22, 261-265. [CrossRef]

45. Hu, S.H. Akaike Information Criterion; Center for Research in Scientific Computation: North Carolina, VA, USA, 2007.

46. Bozdogan, H. Model selection and Akaike's information criterion (AIC): The general theory and its analytical extensions. Psychometrika 1987, 52, 345-370. [CrossRef]

47. Chang, Y.H.; Wong, J.F. Oil price fluctuations and Singapore economy. Energy Policy 2003, 31, 1151-1165. [CrossRef]

48. Erdal, G.; Erdal, H.; Esengün, K. The causality between energy consumption and economic growth in Turkey. Energy Policy 2008, 36, 3838-3842. [CrossRef]

49. Halicioglu, F. An econometric study of $\mathrm{CO} 2$ emissions, energy consumption, income and foreign trade in Turkey. Energy Policy 2009, 37, 1156-1164. [CrossRef]

50. Liu, Y.; Wang, F.; Du, S.C. Influence of environment on air conditioner performance. Heat. Vent. Air Cond. Res. 2006, 36, 110-112.

51. Zhang, Z.B.; Pan, Y.M.; Huang, H.; Jiang, Q. Performance experiment of all fresh air-handing unit with high sub-cooling degree and year-round exergy analysis. HVAC R Res. 2014, 20, 810-818. [CrossRef]

52. He, S.; Chen, W.; Chen, R.; Liu, H. Uncertainty of air conditions cooling capacity measured by enthalpy method. Cryog. Supercond. 2010, 38, 52-55.

53. Lin, J.; Rosenquist, G. Stay cool with less work: China's new energy-efficiency standards for air conditioners. Energy Policy 2008, 36, 1090-1095. [CrossRef]

(C) 2020 by the authors. Licensee MDPI, Basel, Switzerland. This article is an open access article distributed under the terms and conditions of the Creative Commons Attribution (CC BY) license (http://creativecommons.org/licenses/by/4.0/). 